\title{
RELACIONES DE LA INMIGRACION HISPANA CON LA IGLESIA EN EL ÁREA DE WASHINGTON D. C., VIRGINIA Y MARYLAND'
}

\author{
RELATIONSHIPS OF HISPANIC IMMIGRATION \\ WITH THE CHURCH IN THE AREA OF \\ WASHINGTON D. C., VIRGINIA AND MARYLAND
}

J. A. Valero-Matas*, A. Sanchez Bayón**

Resumen: Este artículo es producto de una investigación sobre la inmigración hispana en el tríangulo de Washington D. C., Maryland y Virginia. El estudio pretende analizar las relaciones entre la inmigración hispana y las diferentes iglesias. Los indocumentados, especialmente hispanos han sido un dardo en los procesos electorales en los EE. UU., y sometidos a una permanente inseguridad a ser deportados. Desde hace tiempo las diferentes confesiones son su refugio, pero en las dos décadas estás se han convertido en el principal apoyo y protección. Con este estudio se busca conocer lo más destacado de dicha relación.

Palabras clave: Inmigración hispana; iglesia; Estados Unidos de América; indocumentados e integración.

Abstract: This paper arise of an investigation about Hispanic immigration in the Washington, D. C., Maryland and Virginia area. The research wants to study the relationships between Hispanic

* Profesor Titular de Sociología. Universidad de Valladolid.

** Profesor de la Universidad O'Higgins.

1 Los datos fueron obtenidos entre 2016 y 2017 por J.A. Valero-Matas tras una Visiting Scholar (2015-2016) en Catholic University of America y estancias breves en 2017. 
immigration and different churches. The undocumented Hispanics are being persecuted, deported and in the elections talk down them to win votes. The different confessions have been their refuge for quite long time, but for the past two decades they are the main upholder and protection too. We inquire to know in this relationship the most outstanding.

Key words: Hispanic immigration, church, United States of America; undocumented and integration.

\section{PRESENTACIÓN DEL PROBLEMA, SU PARADOJA Y SU ESTUDIO}

Con la globalización se está produciendo una gran paradoja mientras que en el resto del mundo se está avivando el factor religioso (como parte del debate identitario), en los Estados Unidos de América (EE. UU.), que tradicionalmente había sido un país defensor del factor religioso y de la inmigración está aplicando políticas públicas con regulación restrictiva, incluso de persecución. Ello ha provocado la aparición de un fenómeno, como es el acogimiento y la movilización de las iglesias. Aquí se estudia dicho fenómeno, aterrizándolo en el caso de la inmigración hispana y su desarrollo en Washington D. C. y los Estados vecinos (Maryland y Virginia - que originalmente cedieron parte de su territorio para la constitución del Distrito de Columbia).

Ahondando en el problema detectado en las últimas décadas, como es la recurrente amenaza política (desde la Adm. H.W. Bush hasta Obama - bautizado con el juego de palabras Deporter in Chief) al inmigrante indocumentado o dreamer ${ }^{2}$. La singularidad de este tipo migrante radica en su confesionalidad cristiana y el recurso en consecuencia de las iglesias para su integración en el país, incluso para sortear las persecuciones (Sección 287(g) de la Ley federal de Inmigración; Ley SB1070 de Arizona, que considera delito llevar en el coche a un inmigrante ilegal).

2 Hace relación a los jóvenes hispanos menores de edad no acompañados que llegaron a los EE. UU. 
Relaciones de la inmigracion hispana con la Iglesia en el área de Washington...

INMIGRANTES INDOCUMENTADOS Y DEPORTADOS DESDE 1989

\begin{tabular}{|c|c|c|c|}
\hline Año/Adm. & $\begin{array}{l}\text { Indocumentados } \\
\text { (millones) }\end{array}$ & Deportaciones & Porcentaje(\%) \\
\hline 1989 | H. W. Bush & 2.00 & 34,427 & 1.7 \\
\hline 1990 | H. W. Bush & 3.50 & 30,039 & 0.8 \\
\hline 1991 | H. W. Bush & 4.10 & 33,189 & 0.8 \\
\hline 1992 | H. W. Bush & 4.60 & 43,671 & 0.94 \\
\hline 1993 | Clinton & 4.90 & 42,542 & 0.86 \\
\hline 1994 | Clinton & 5.30 & 45,674 & 0.86 \\
\hline 1995 I Clinton & 5.70 & 50,924 & 0.89 \\
\hline 1996 I Clinton & 6.30 & 69,680 & 1.1 \\
\hline 1997 I Clinton & 6.80 & 114,432 & 1.6 \\
\hline 1998 I Clinton & 7.10 & 174,813 & 2.4 \\
\hline 1999 | Clinton & 7.80 & 183,114 & 2.3 \\
\hline 2000 I Clinton & 8.60 & 188,467 & 2.1 \\
\hline 2001 I W. Bush & 9.30 & 189,026 & 2.03 \\
\hline 2002 I W. Bush & 9.40 & 165,168 & 1.75 \\
\hline 2003 I W. Bush & 9.70 & 211,098 & 2.1 \\
\hline 2004 I W. Bush & 10.40 & 240,665 & 2.3 \\
\hline 2005 I W. Bush & 11.10 & 246,431 & 2.2 \\
\hline 2006 I W. Bush & 11.60 & 280,974 & 2.4 \\
\hline 2007 | W. Bush & 12.20 & 319,382 & 2.6 \\
\hline 2008 I W. Bush & 11.70 & 463,946 & 4.0 \\
\hline 2009 | Obama & 11.30 & 296,713 & 2.6 \\
\hline 2010 I Obama & 11.40 & 381,962 & 3.3 \\
\hline 2011 I Obama & 11.50 & 388,409 & 3.3 \\
\hline 2012 | Obama & 11.20 & 419,384 & 3.7 \\
\hline 2013 | Obama & 11.30 & 435,498 & 3.8 \\
\hline 2014 | Obama & 11.30 & 414,481 & 3.6 \\
\hline
\end{tabular}

Fuente: DHS \& OIS, 2014. 
Con la actual Trump Administration parece que las políticas contra la inmigración indocumentada, especialmente la hispana, se van intensificando. Sirva como ilustración el aumento de la violencia simbólica, las declaraciones genéricas contra inmigrantes mexicanos (y el muro en la frontera) o contra los salvadoreños (y las deportaciones masivas). Ahora bien, en relación al objeto de este estudio, se desea ofrecer una mínima muestra de casos recientes habidos por todo el país donde se acogieron a sagrado: un inmigrante hispano con leucemia en Shadow Rock United Church of Christ de Phoenix en febrero de 2018, un mexicano en Methodist Church de Philadelphia en octubre de 2017, un salvadoreño en First Unitarian Church de Austin en septiembre de 2017, una guatemalteca en Iglesia de Dios Pentecostal de New Haven en agosto de 2017, etc.) ${ }^{3}$, para introducirlo en el contexto del asunto concreto a tratar aquí, cómo los inmigrantes hispanos encuentran auxilio en las iglesias del triángulo $D C, M D$ y $V A$ frente a políticas de persecución, bajo la firme creencia religiosa de estar dando cumplimiento al sermón de las bienaventuranzas, y la convicción civil de dar continuidad al muro de separación entre Iglesia y Estado (atribuido a Jefferson).

El papel de la religión, como factor social es muy importante en la integración de los inmigrantes. A su vez, la inmigración revitaliza el factor religioso y ayuda a dar dinamismo y forma a las sociedades receptoras, impactando profundamente en su economía, su política, su cultura, etc. Tal es su relevancia que la vida social se ve afectada por la demografía de la inmigración; máxime en los EE. UU, donde su historia está basada en la inmigración. Muchas de las instituciones públicas y privadas, religiosas y seculares comparten la responsabilidad de ayudar a los inmigrantes e incorporarlos a la sociedad estadounidense. No obstante, una singularidad estadounidense es que, tradicionalmente, han sido los grupos religiosos quienes han jugado un papel central en ayudar a los nuevos inmigrantes a asentarse y convivir en el país. Los grupos religiosos ayudan a los inmigrantes a hacer valer sus derechos económico-sociales: encontrar vivienda y empleo; ofrecer formación para la integración (enseñando el idioma, el sistema legal, etc.);

3 Incluso, han surgido varios movimientos religiosos de auxilio organizado mediante internet. The Interfaith Movement for Human Integrity is part of the National Sanctuary Movement. Sin olvidar las diversas páginas electrónicas donde cuentan sus experiencias, del tipo Made into America: inmigrants stories archive (URL: http://madeintoamerica.org). 
incluso, preparar para actuar ante una urgencia médica, policial, etc. Su labor es hasta intergeneracional al ayudar también a negociar entre generaciones de origen inmigrante (ante problemas como el desarraigo, el choque cultural, etc.). En definitiva, las iglesias asisten a los inmigrantes para buscar su camino de integración en una sociedad compleja brindándole así ayuda de toda índole (HondagneuSotelo, 2007; Treviño, 2006; Vázquez y Friedmann, 2003).

Además del conjunto de ayudas mencionadas, las iglesias y sus organizaciones se convierten en instrumentos fundamentales para el mantenimiento de los valores culturales de los inmigrantes, pero también de canalización entre los valores culturales de la sociedad de origen y los valores de la sociedad de acogida. En la nueva inmigración, ya no se produce una asimilación total sino una asimilación segmentada, manteniendo los elementos de identidad local y la nueva identidad, sin que ello entre en confrontación. Esto permite trabajar con mayor flexibilidad y por lo tanto, mayor integración. Es a través de la promoción de la fe y actividades que simultáneamente fomentan la integración en la sociedad y cultura estadounidense con la preservación de la cultura e historia de las diferentes minorías nacionales hispanas. Tal y como acontece actualmente con muchas de estas minorías que pasan por un proceso de asimilación segmentada en el trabajo. Hirschman (2004) dice que la centralidad de la religión de las comunidades de inmigrantes se puede resumir en tres palabras, y lo ha denominado la búsqueda de las tres R, refugio, respetabilidad y recursos (p. 1228):

Las tesis de las tres R's de Hirschman son abordadas con cierta reflexión crítica por Kivisto (2014: 55). La primera R, la religión es refugio para los inmigrantes y habiendo sido expresado por Thomas, Handlin, Herberg y otros, la inmigración es inherentemente desorientadora y una experiencia alienadora. La religión en la medida que puede proveer de refugio a los inmigrantes, los ayuda a superar dicha experiencia. Respecto a la respetabilidad, aludiendo a otros autores, (Honneth, 2007; Alexander, 2006) los inmigrantes se enfrentan al reto de no ser simplemente tolerados, sino de ser aceptados, abrazados con sus valores diferentes y a su vez considerados iguales.

Estos conceptos entrelazados de reconocimiento y respeto tienen un lineamiento teórico complejo. Quizá una de las cuestiones a plantearse resida en qué medida se ve el inmigrante, y cómo se 
identifica como miembro plenamente de los EE. UU., para compartir su identidad con los ciudadanos nacidos estadounidenses, y a largo plazo sentirse completamente estadounidense. Se plantea que el interés está en conocer en qué medida la iglesia adopta un papel facilitador en todo este proceso. Este aspecto, dependiendo del estudio que se tome y de la iglesia seleccionada se concibe como un catalizador de esta integración sin perder sus valores identitarios. Por ejemplo, un estudio realizado por Chen (2008) sobre diferentes comunidades religiosas de inmigrantes, cristianos y budistas observó que cada iglesia buscaba diferentes vías de identificación con la sociedad receptora (p.67). Tras este estudio, Kivisto (2014) expresa que para cristianos y budistas la participación religiosa pasa a ser un instrumento de identificación con los significados de la sociedad estadounidense, pero de aspectos selectivos de su cultura. Por lo tanto, existe una respetabilidad con la nación receptora, pero sin perder la esencia de la identidad de la nación de origen. De ahí que entren en confrontación ciertos aspectos y valores culturales no previstos en la sociedad de acogida y fuertemente arraigados en la sociedad de origen. Por último, la tercera $\mathrm{R}$, la religión como recurso puede servir de puente entre la cultura de la nación de origen y la cultura del nuevo asentamiento, ayudando a los inmigrantes a ajustarse a su nuevo asentamiento (p.71-73).

La religión en el mundo del migrante tiene mucha importancia, concretamente en los EE. UU., puesto que la iglesia se transforma en un espacio de acogida, formación, integración y lo catapulta al mercado. El proceso migratorio, especialmente hispano, conlleva un proceso de reafirmación de la fe. Es decir, implica una experimentación del core belief, como dice Levitt (2003:251) la religión desempeña un rol crucial en la construcción de la identidad, en la producción de significados y en la formación de valores (p.251). Siguiendo con Levitt (2008) la religión es una fuerza positiva infrautilizada que científicos y activistas sociales no puede por más tiempo permitirse el lujo de ignorar. No se puede obviar que las iglesias, particularmente, la católica y protestante se organizan en grupos que sirven para la acción social como política para defender los intereses cívicos y religiosos de los inmigrantes (p.766)..

Otro aspecto significativo es como la diferenciación étnica marca una discriminación dual entre creyentes de una misma confesión en los EE. UU.: los WASP y el resto. Fijando la mirada en la vieja inmigración, la Iglesia católica estadounidense conscientemente 
dotó de sacerdotes étnico próximos a las minorías nacionales para que siguieran practicando la fe. Esta no marca la política de las iglesias en EE.UU. pero dicho efecto permanece indirectamente en católicos, protestantes y ortodoxos.

Para la inmigración contemporánea, la religión continua la forja de una identidad cultural y propósitos sociales. Muchas de las congregaciones a las que asisten los inmigrantes son percibidas en la zona como un servicio particular del grupo étnico-cultural: con frecuencia las prácticas religiosas se realizan en sus propios idiomas excluyendo a los nativos nacidos en los EE. UU. Quizá por razones sociales y culturales, y en menor medida teológicas, temen que los diferentes de valores etnoculturales ocupen los bancos de sus iglesias.

Las religiones no se limitan, por lo tanto a conservar y a transmitir la identidad etnocultural, sino a transformarla, influyendo en la modalidad con la que los inmigrantes se adaptan y se transforman en el proceso de inserción en la sociedad receptora (Ambrosini, 2008:20).

Con estos mimbres, el estudio se divide en tres secciones; contextualización de las iglesias y los hispanos en los EE. UU.; análisis de los resultados: discusión y observaciones; y reflexión y conclusiones que arrojen luz sobre la relación entre la inmigración hispana e la iglesia.

\section{EL CONTEXTO DE LAS IGLESIAS E HISPANOS EN EE.UU.}

La participación en una iglesia, bien sea católica, ortodoxa o protestante implica que los inmigrantes se encuentren identificados con las creencias religiosas y sus prácticas, y en qué medida estás los apoyan en su primer contacto con el país. Según Díaz (2006:100) la mayoría de los inmigrantes son asimilados por la cultura dominante dejando atrás su cultura; pero en el caso de los hispanos, no sufren ese proceso, poniendo en tela de juicio dicha teoría. A juicio de Díaz se produce esto, porque la inmigración hispana se refugia en la fe, en la religión donde conforman núcleos de defensa cultural. La iglesia mediante su apostolado hispano los protege ante la situación de abandono e inseguridad del recién llegado a otro país.

Por otra parte, aparecen importantes diferencias de afiliación religiosa entre los hispanos, particularmente, entre latinos (nacidos 
en los EE. UU.) y los latinoamericanos (nacidos en el exterior). Entre los hispanos nacidos en el extranjero es bastante probable que su pareja sea nacida en los EE. UU. y católica. Las estimaciones sugieren que más del $50 \%$ de los hispanos nacidos en EE. UU. son católicos, frente al 70\% de los hispanos nacidos en el extranjero (Pew Research Center, 2007; Taylor et al., 2012). Espinosa et al., (2003) muestran como las sucesivas generaciones de latinoamericanos (nacidos el EE. UU.) son progresivamente menos católicos: el $74 \%$ para la primera generación, el $72 \%$ para la segunda generación y el $62 \%$ para la tercera generación. Tendencias confirmadas por Foley and Hoge (2007:65) exponiendo que los inmigrantes se vuelven menos religiosos cuanto más tiempo permanecen en los EE. UU., afectados por ese intento de "blanquearse", asimilando los valores de la sociedad WASP (p.65). Barranco (2016) habla del declive de la fe en los EE. UU., resultando aún más pronunciado por el auge de ateos y agnósticos (p.261). De hecho, un amplio número de cristianos estadounidenses no asisten a la iglesia (ni a servicios ni actividades comunitarias), como tampoco se involucran socialmente. Esta actitud implica un declive de las creencias que sustentaron los valores de los EE. UU.

En estas interpretaciones se puede percibir que existen importantes aristas y ciertas contradicciones, entre otras cuestiones porque no han tenido presente las últimas oleadas migratorias, especialmente las de los hispanos de Centroamérica, quienes vienen con una profunda defensa de su fe. Esto ha supuesto una revitalización en la sociedad estadounidense de los valores cristianos. Como señala Castleberry (2015) los nuevos peregrinos son consecuencia de las oleadas migratorias y fundamentalmente el cristianismo está siendo revitalizado por los inmigrantes hispanos. Por lo tanto la fe cristiana está asegurada en los EE. UU. (p. 10).

\section{METODOLOGÍA}

\subsection{Distribución de la muestra}

La muestra ha sido extraída en los Estados de Virginia y Maryland, más la capital, Washington D. C. ${ }^{4}$. La recolección se ha llevado a cabo

4 Se ha elegido esta área porque la mayoría de los estudios en EE. UU. los incluye como área conjunta de estudio de la inmigración. 
en centros de reunión aconfesional y espacios de culto religioso de los hispanos, diferenciando entre administrativamente regulados y no regulados. La selección de la muestra ha sido aleatoria buscando la mayor representatividad de las nacionalidades hispanas en cada espacio geográfico. Las personas participantes respondieron a un cuestionario de manera anónima y conforme a los estándares de cualquier investigación sociológica.

Se seleccionaron personas mayores de 18 años. Prácticamente ha sido el mismo porcentaje de mujeres $(\mathrm{n}=104 ; 49,76 \%)$ y varones $(\mathrm{n}=105 ; 50,24 \%)$. Por etapas educativas, estudios primarios $(58,13 \%)$, secundarios $(30,14 \%)$, bachillerato $(5,74 \%)$ y universitarios $(5,74 \%)$, ninguno ha manifestado carecer de estudios o ser analfabeto. En cuanto a la práctica religiosa, los porcentajes han sido ateo, agnóstico o no identificado con ninguna religión $(3,8 \%)$, católicos $(69,38 \%)$, evangélicos $(14,83 \%)$ y protestante $(11,96 \%)$. Finalmente, se ha atendido a la situación administrativa discerniendo entre los migrantes hispanos en situación irregular y regular: y en ésta última entre quienes poseen la Green Card, y visa de trabajo. Irregular $(70,81 \%)$, Green Card $(9,09 \%)$ y visa de trabajo $(20,10 \%)$.

\subsection{Instrumento}

Los instrumentos utilizados en la investigación han sido el cuestionario (cues) para recoger información sobre su situación laboral, familiar, periodo de estancia, situación administrativa, práctica religiosa, etc. Con un total de 25 preguntas, 20 abiertas, y cinco venían acompañadas de una frase corta donde los consultados debían responder a una escala de Likert de cinco puntos (1 a 5) expresando su grado de acuerdo o desacuerdo con la cuestión. La entrevista semiestructurada (entrev) con una estructura de 20 cuestiones similares a las aparecidas en el cuestionario. Y un grupo de discusión (gdisc) con ocho personas, cuatro varones y cuatro mujeres de diferentes países hispanoamericanos ${ }^{5}$. El cuestionario como la entrevista se han elaborado teniendo presente los análisis desarrollados por diferentes think-thank: Pew Research Center $y$ Migration Policy Institute.

5 Los nombres de las personas que aparecen en el texto producto de la investigación son todos ficticios. 


\subsection{Procedimiento}

La investigación abarca diferentes cuestiones, aunque intenta centrarse en la averiguación de la auténtica relación del inmigrante hispanoamericano con las diferentes confesiones cristianas en los EE. UU., ahondándose en sus sinergias y retroalimentaciones; en cambio, se deja para otros estudios posteriores, la indagación sobre las relaciones entre las iglesias de origen y receptoras de dicha migración.

Por consiguiente se han analizadolos diferentesítems, inicialmente desde un punto de vista descriptivo, estableciéndose después diferenciaciones entre los segmentos mediante análisis estadísticos bivariantes y multivariantes. Extrayendo las diferencias (criterio de significación $\mathrm{p}<.05$, y comparando los diferentes subgrupos mediante un análisis de varianza (anova), a modo de determinar si los grupos son todos parte de una población más grande o poblaciones separadas con características diferentes. De manera que el estadístico de la desviación típica permitirá cuantificar e interpretar la magnitud de la diferencia. Se ha utilizado el estadístico de Chi-cuadrado como prueba de contraste para las variables categóricas. Finalmente, se ha recurrido a un análisis de correspondencias múltiples, pues permite analizar las relaciones de dependencia e independencia de un conjunto de variables categóricas.

\section{ANÁLISIS Y DISCUSIÓN DE LOS RESULTADOS}

Antes de entrar propiamente en el análisis y discusión de resultados es oportuno señalar cuatro aspectos propedéuticos extraídos de la investigación.

- Las iglesias, en su dimensión subjetiva, auxilian a los inmigrantes a integrarse y encontrar un puesto de trabajo.

- Las iglesias, en su dimensión objetiva, son lugar de refugio y apoyo ante las injusticias de la deportación masiva de las políticas migratorias estadounidenses.

- Las iglesias, en su dimensión sistémica, son organizaciones de encuentro, donde los inmigrantes mantienen y refuerzan su identidad (interactúan con el país de acogida).

- Los inmigrantes administrativamente irregulares son más activos en la participación religiosa. 
Tras el trabajo de campo y posterior análisis se han obtenido los siguientes resultados estadísticos: el 71,77\% de los encuestados practican y/o asisten a la iglesia, y de estos, el 69,38\% pertenecen a la iglesia católica. Al respecto, se debe decir que la Iglesia católica en los EE. UU. se está nutriendo de los hispanos (Pew Research Center, 2015). Más aún, sobre el catolicismo en transición en EE. UU., D’Antonio, Dillon, \& Gautier (2013) sostienen que un sector importante de estadounidenses viene abandonando el catolicismo no afiliándose a otras creencias, mientras los hispanos que van llegando están aumentando la ratio de católicos (p.98). Pese a la divergencia de lecturas al respecto, si coincide la doctrina en el problema que ha derivado en una segregación socio-religiosa persistente en los EE. UU.: en muchas iglesias se separa al fiel de origen anglosajón de otros (cada parroquia ofrece servicios según comunidades). Esto no necesariamente implica la existencia de sacerdotes hispanos para los hispanos y anglosajones para los anglosajones, sino una atención a la diversidad que requiere de un apostolado hispano para comprender más las necesidades de dicho colectivo (heterogeneidad idiomática y cultural) ${ }^{6}$. Es parte de la lógica del melting pot o crisol cultural.

Si se cruzan las variables sexo y práctica religiosa se aprecia como las mujeres se encuentran más identificadas con el hecho religioso, probablemente por transcendencia e identificación con la Virgen María (Pew Research Center, 2015 y 16). El peso conferido al factor religioso en la mujer hispana proviene de la actitud que ofrece la iglesia para afrontar los problemas sociales y la discriminación imperante.

Otro resultado a destacar es que la población estadounidense en su mayoría es cristiana, y como pone de relieve el "US Religion Census" sólo el $28 \%$ se declara católica, resultando la minoría mayoritaria entre las confesiones cristianas del país. Si las proporciones se trasladan a la inmigración hispana, los datos varían sustancialmente, porque el $62,4 \%$ de los inmigrantes hispanos se identifican como católicos frente a 21,7\% evangélicos, y el resto a otras creencias, no creyentes o no han declarado o contestado confesión.

A continuación se ahonda en los resultados de los apartados específicos de los cuestionarios, entrevistas y dinámicas.

6 Es cierto que muchos de los hispanos no hablan inglés, a pesar de llevar muchos años viviendo en el país. Los hijos son casi todos bilingües. En casa hablan español y en el colegio inglés, la situación varía cuando los padres hablan inglés, entonces la tendencia es hablar inglés en casa, perdiendo lo bilingüe por un español "de andar por casa". 


\section{1. "Asistencia a la iglesia"}

La asistencia a la iglesia como fuente de integración también es un acto de reafirmación de la cultura, como sugiere Hirschman (2004): los eventos y prácticas religiosas no son solamente rituales de fe, también de religiosidad popular proclamando actos de reafirmación cultural de pertenencia a una comunidad étnica. Además de estas observaciones, cabe destacar que la iglesia en EE. UU., pasa a ser una forma de expresión, especialmente para los inmigrantes irregulares que no tienen voz ni voto. Son una inmigración ciudadanamente invisible, mientras que es una inmigración laboral visible. Por esto, los rituales y celebraciones como prácticas de la religiosidad, los permite crear formas alternativas de expresión y de pertenencia, cualidades que resultan también de la memoria, así como formas de recordación y vuelta al lugar de origen. Pero también de la creatividad y del contexto, las cuales se potencian en el espacio público posibilitando la formación de identidades transnacionales que podrían llegar a ser también identidades postnacionales hacia la construcción de otras formas de ciudadanía (Soysal, 1994; Levitt, 2004; Hondagneu-Sotelo et al., 2004).

Centrando la atención en el ítem "asistencia a la iglesia". Los católicos son los más participativos, entre otras cuestiones porque muchas parroquias católicas tienen más horas de apertura, posiblemente por tener anejos centros de enseñanza (desde elementary school hasta high school). Pero también existe un elemento interesante, la religiosidad en muchos casos viene con esa implicación identificativa con la fe cristiana desde sus espacios de origen. Muchos proceden de áreas rurales donde el sacerdote es su punto de referencia, de ahí, que algunas nacionalidades no sientan dicha identificación por proceder de áreas urbanas menos referenciadas. Como sugiere Tönnies (2009): las relaciones de interacción de la sociedad moderna donde se pierde esa voluntad natural como en las áreas rurales por una voluntad racional de las zonas urbanas producto de la modernización y pérdida del entronque comunitario-cooperativo. El hecho de buscar más una aplicación práctica, implica un mayor alejamiento de la iglesia, buscando una acción rápida y secular. Otra causa diferencial entre protestantes y católicos puede ser que la mayoría de la vida social de los protestantes hispanos se desarrolla en las congragaciones locales (Mulder, Ramos y Martí, 2017). Pero no sólo esto establece la diferencia, sino también que estas comunidades interactúan poco entre sí, perdiéndose muchos recursos al no aunar 
sus potencialidades. Si interaccionarán más se podría dotar de más recursos para hacer frente a los problemas sociales y resolver muchos más asuntos de la inmigración.

GRÁFICO 1

Asistencia de católicos a la iglesia

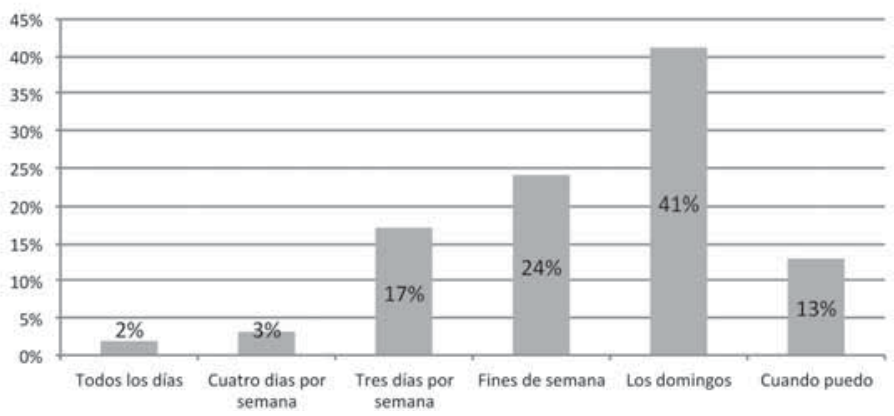

Fuente: elaboración propia.

La mayoría de los católicos asisten a oficios religiosos, principalmente domingos y fiestas de guardar, así lo consigna un $41 \%$. En segundo lugar están quienes asisten fines de semana y tres días por semana, y como se recoge en el gráfico 4 se corresponde con quienes pertenecen a algún grupo de acción religiosa. Un número significativo asisten cuando puedo según muestra el gráfico 1.

GRAFICO 2

Asistencia evangélicos a la Iglesia

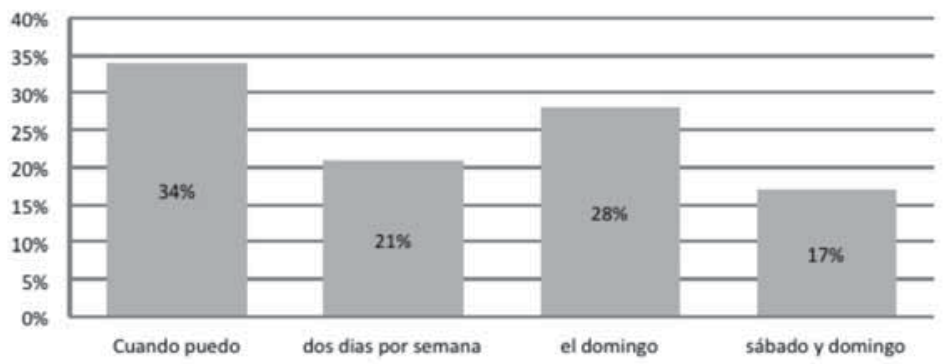

Fuente: elaboración propia. 
En el caso de los evangélicos, su asistencia a la iglesia está condicionada por razones laborales: muchos de ellos — como así lo comentaban-, los domingos se veían obligados a trabajar, y por lo tanto condiciona su asistencia al culto. En segundo lugar, aparecen quienes declaran su asistencia dominical (28\%), mientras un 21\% manifiesta su afluencia dos días por semana. Respecto a este punto, decían acudir a la iglesia fundamentalmente el jueves y el domingo. El jueves era el día del comentario y reflexión de los textos sagrados y el domingo día de dar gracias a Dios para empezar una nueva semana.

GRAFICO 3

Asistencia protestantes a la iglesia

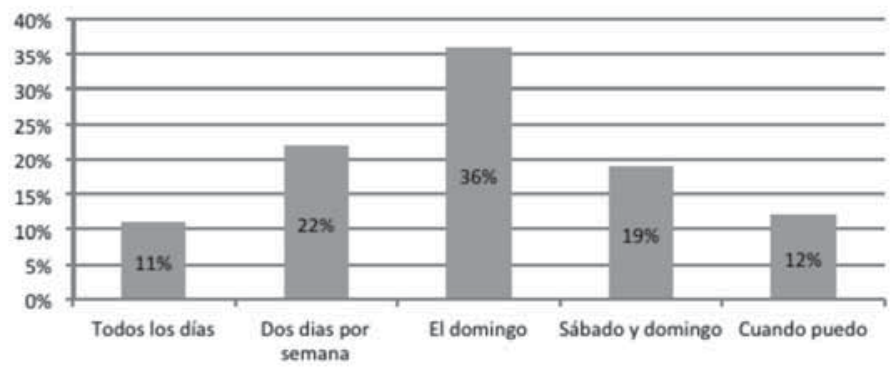

Fuente: elaboración propia.

Los creyentes protestantes presentan un abanico más amplio respecto a los evangélicos. El 36\% que han respondido al cuestionario, declaran concurrir al templo los domingos y un $22 \%$ dos días por semana. Si bien, la participación de estos últimos en las actividades de la comunidad recae en lectura de la Santa Biblia, mejorar las instalaciones del tabernáculo y en los grupos de asistencia a los necesitados. Por el contrario, otros exponen las dificultades para asistir más al baptisterio: la distancia, la atención a los miembros de la familia, y al puesto de trabajo que los obliga a trabajar durante el fin de semana.

En los tres colectivos se advierten dificultades de los feligreses para concurrir a los oficios religiosos, las obligaciones laborales dificultan su asistencia obstaculizando adecuar estas con sus necesidades y compromisos espirituales. 
Finalmente, las parroquias operan a nivel micro y contribuyen a la formación de comunidades étnicas, las cuales podrían diseñar comunidades cerradas y autorreferenciales. Pero también ayudan a conectar a sus participantes y asistentes a las parroquias y a las comunidades étnico/nacionales hacia redes más amplias en el espacio público, las cuales no se circunscriben necesariamente al campo religioso (Rivera-Sánchez, 2007:265).

\section{2. "Pertenencia a grupos de acción religiosa"}

La participación en la actividad religiosa resulta muy importante para los inmigrantes, especialmente quienes se encuentran en una situación administrativa complicada, puesto que las iglesias suelen ser un centro de refugio, satisfacción y proyección del inmigrante en la sociedad de acogida. Así lo señala una de las conclusiones del estudio de la Templeton Foundation (2007) que las personas con una vida religiosa comprometida y participación en las actividades de las congregaciones, su vida era más satisfactoria. Lim y Putman (2010) extraían del estudio y concretamente de este apartado que la gran satisfacción de estas personas se debe a la asistencia que los brinda los servicios religiosos, como son la creación y prolongación de las redes sociales de las diferentes iglesias.

Con acuerdo a los resultados del estudio y centrando la atención en el gráfico 4, se advierte que los más identificados con la participación desde las diferentes subagrupaciones religiosas, son los católicos con un 39,8\% y los menos, los evangélicos con un 13,70\%. Aquí cabe resaltar dos características presentes en evangélicos y protestantes, pero no en los católicos. Por un lado, la membresía cuyo porcentaje es muy bajo, en algunas parroquias no llega ni a los 50 miembros. Y en segundo lugar, la actividad laboral principal del pastor está fuera de la iglesia. Esto dificulta la apertura diaria del templo y la puesta en escena de suborganizaciones colaborativas de acción religiosa.

Si bien, en los protestantes se percibe un leve aumento con respecto a los evangélicos implicados en actividades de acción religiosa. Estos dicen dedicarse a actividades más orientadas a la integración religiosa y social, como a la profundización de las creencias religiosas, porque aborda y afianzan la espiritualidad con Dios. Quizá debido a cuestiones básicas de la propia liturgia sean más proclives a actividades de identidad religiosa, grupos de saneamiento espiritual, fundamentos de la fe, enseñanza de la liturgia, etc. 
Grafico 4

\section{Pertenencia a grupos de acción religiosa}

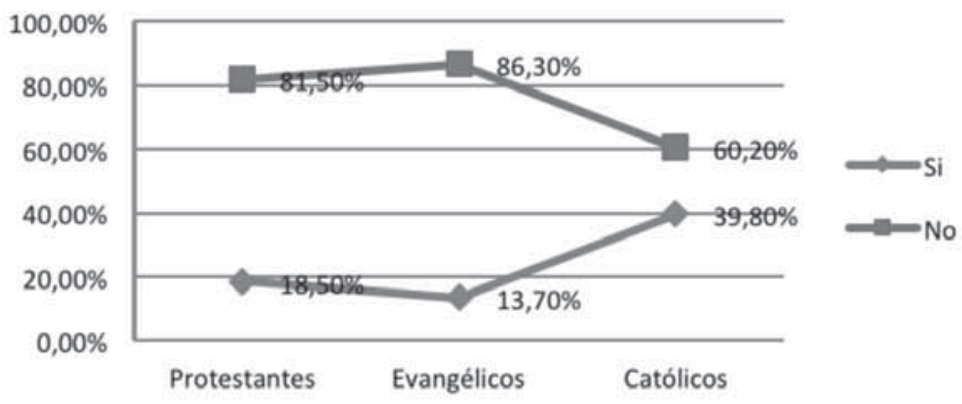

Fuente: elaboración propia.

En lo concerniente a la creencia protestante quienes más participan en las asociaciones de voluntariado son aquellos con una situación regular, y sus acciones se orientan a ayudar a los sin techo, los mercadillos navideños, etc. En cambio, en el perfil indocumentado disminuye considerablemente su presencia. Ante la escasez de miembros puesto que la mayoría se encuentran en situación irregular resulta complicado desplegar programas para ayudar al colectivo. Un pastor de DC (entrev) flexionaba "ante la dificultad de lograr una mayor integración e implicación de los inmigrantes hispanos mediante programas socio-económicos, nos vemos obligados a fortalecerlos a través del conocimiento de las escrituras y de la fe protestante".

Tras realizar un análisis de correspondencias múltiples se descifra que las organizaciones de la iglesia católica son más proclives a ayudar y con mayor asistencia de inmigrantes indocumentados. Según esto, los inmigrantes católicos de procedencia centroamericana y mexicana son el colectivo con mayor pertenencia a grupos de acción religiosa. Por lo tanto se encuentran más identificados con los valores de la Iglesia católica.

Por otro lado, los evangélicos no suelen pertenecer a grupos religiosos, por lo antedicho, y están formados por iglesias pequeñas con poca membresía. Mientras los protestantes no ser identifican con grupos y se encuentran alejados de cualquier consideración de este orden. 
GRAFICO 5

\section{Gráfico simétrico de las variables}

(ejes F1 y F2: 81,87\%)

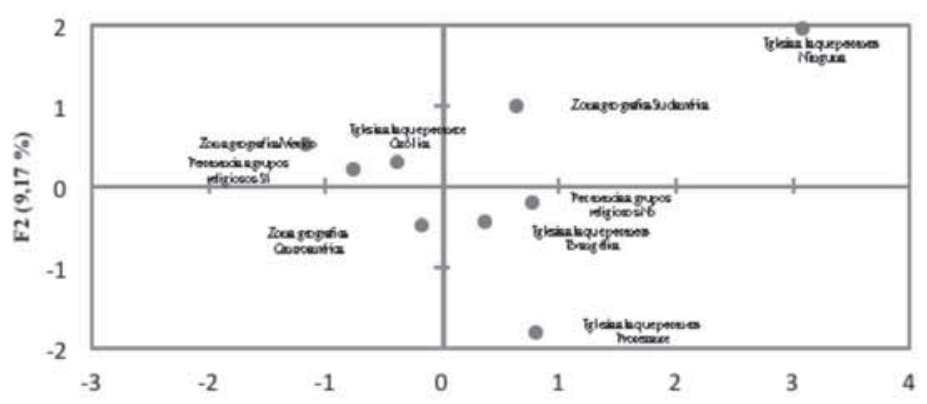

Fuente: elaboración propia.

Las observaciones de Hirschman (2004: 1230) van en esta línea, pues ve en la participación religiosa, sobre todo en confesiones minoritarias, la posibilidad de acumular capital social útil por ejemplo, para el progreso en el ámbito laboral, ofreciendo en ciertos casos oportunidades para adquirir los roles de responsabilidad inherentes a la entrada en verdaderas y específicas "carreras» dentro del ámbito pastoral: sobre todo como ministros de culto. Más en general, todavía hoy: "los inmigrantes y sus familias van a la iglesia para obtener informaciones respecto al alojamiento, las oportunidades de trabajo y otros problemas. Las iglesias ofrecen cursos para ayudar a los padres ancianos. Los jóvenes inmigrantes o las segundas generaciones suelen frecuentar la iglesia para ser ayudados en sus tareas, para participar en actividades sociales o para encontrar futuros novios o novias que probablemente obtendrán la aprobación de sus padres" (Hirschman, 2004, p.1.229)

\section{3. "Ha recibido ayuda de la iglesia"}

En este ítem se preguntaba si habían recibido alguna ayuda de la iglesia para encontrar trabajo, una vivienda, arreglar los papeles para adquirir la nacionalidad norteamericana, un puesto de trabajo, aprender inglés, etc.

Dependiendo de las diferentes congregaciones, del tamaño, de la identificación con el colectivo hispanoamericano y de las demandas de 
los inmigrantes la realidad es muy variada. Como viene siendo habitual en todas las respuestas, la creencia católica es la más dinámica y más activa con el grupo hispano. A pesar del crecimiento de otras creencias dentro del colectivo y de su retroceso hacia la doctrina católica y otros credos en general (Pew Research Center, 2014 y 2016).

Contemplando las valoraciones sobre la ayuda de la iglesia en los evangélicos pocos manifiestan haber recibido ayuda de su comunidad religiosa, tan sólo un 4,30\% frente al 42,60\% que no. Pero también existe un grupo significativo indicando no haber solicitado ayuda de la comunidad $(53,10 \%)$.

GRAFICO 6

Ha recibido ayuda de la iglesia

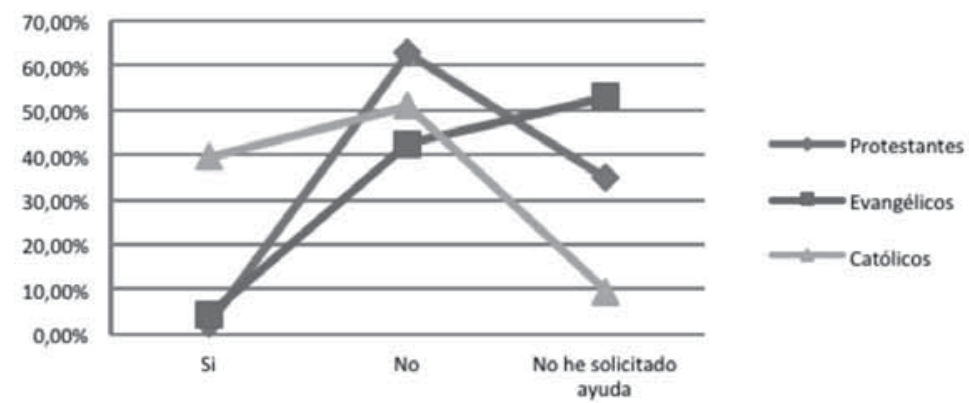

Fuente: elaboración propia.

Son varias las variables intervinientes en el proceso. Tomando algunas de las reflexiones de feligreses entrevistados, unos manifestaban desconocer que su comunidad los pudiera ayudar en materia de: obtener los papeles para la Green Card, encontrar trabajo, aprendizaje del inglés, ayuda alimentaria, etc. Otros si sabían de ello, bien por haber residido en otros lugares o tras comentarios con otros hispanos, pero no lo solicitaban porque la comunidad no podía hacer frente a esos problemas. María (gdisc) relataba que "cuando mi esposo y yo fuimos a hablar con el Pastor de nuestro asunto para intentar naturalizarnos porque estamos ilegales, nos dijo que lo iba a mirar, a los pocos días nos llamó y nos dijo que nuestra situación era muy compleja y había pocas posibilidades de lograrlo. Además, si 
seguíamos adelante posiblemente sí las autoridades de inmigración detectaban nuestra presencia nos deportarían. En definitiva, no nos podía ayudar".

Carlos (gdisc. VA) "a mí no me han ayudado puesto que desconocía que la comunidad religiosa pudiera emprender acciones para regularizar mi situación y así obtener la naturalización. Dicha cuestión no sólo mejoraría mi situación sino que podría ir a ver a mi familia, pues llevo 13 años en este país, y no he regresado a El Salvador por miedo a no volver por las leyes norteamericanas".

Una mujer de Honduras evangélica (entrev. MD) "me enteré que en CASA Maryland ayudaban a los inmigrantes indocumentados a regularizar la situación en los EE. UU. Gracias a ellos, logré regularizar mi situación de 16 años en este país, con la constante amenaza de ser deportada. Ahora tengo la Green Card y estoy a la espera de poder adquirir la nacionalidad norteamericana. Desde entonces mi vida ha cambiado totalmente. Ya no tengo que vivir con esa incertidumbre de ser deportada. Vivir así es muy duro. [...] Las autoridades norteamericanas deberían preguntarse ¿Por qué salimos? y las penurias que se pasan durante el trayecto hasta llegar aquí. Algunos pierden la vida [...] a pesar de todas las dificultades, la iglesia ha ayudado a muchas personas a encontrar su sitio en el país".

Un pastor evangélico (entrev. DC) declaraba las dificultades existentes para poder ayudar a los hispanos irregulares. "Para ello, se requiere unos buenos abogados, un buen conocimiento de su historia de vida desde su llegada, conocer las posibilidades de lograr el objetivo porque de lo contrario la deportación está asegurada. Es decir, se necesita mucho dinero. Además, no contamos con mucha gente ni con suficientes recursos, esto impide poder abordar los problemas como quisiéramos."

Pocas iglesias cuenten con un/a pastor/a de ascendencia hispana ${ }^{7}$. En el caso de una iglesia protestante en Montgomery County, la pastora (entrev. MD) de ascendencia hispana expresaba que la gustaría poder hacer más por los hispanos en situación irregular, pero ellos cuentan con pocos recursos, y los suelen derivar a CASA

7 Las iglesias evangélicas cuentan con el mayor porcentaje, porque muchas son creadas por pastores venidos de algún país de Hispanoamérica. 
Maryland ${ }^{8} \mathrm{u}$ otros centros con más recursos. "Nosotros ayudamos espiritualmente a los inmigrantes indocumentados, pero claro, no tenemos recursos materiales ni económicos [...] somos una comunidad pequeña con pocos recursos, especialmente financieros. Muchos de nuestros feligreses son indocumentados y con problemas para hacer frente a todos los gastos requeridos en este país. Cuando algún miembro de la comunidad no tiene trabajo y el resto de los parroquianos se enteran de algo, se lo hacen saber. [...] Pero también es conocido que la comunidad hispana en este sentido está muy unida, y saben dónde preguntar para encontrar empleo".

Los hispanos de credo protestante vienen a tener un comportamiento similar a los miembros de la fe evangélica. Tan sólo el 2,30\% de los consultados dice haber tenido ayuda de su comunidad religiosa para regular su situación. Un $62,90 \%$ no ha recibido ayuda de su iglesia y el $34,80 \%$ no ha tratado este tema con los miembros de su comunidad religiosa. Conviene apuntar dos asuntos, por un lado, la comunidad protestante en su mayoría es de procedencia europea y con mucho arraigo en la comunidad anglo, manteniendo cierta distancia con la comunidad hispana. Esto no implica la inexistencia de protestantes hispanos. La comunidad es muy pequeña. El segundo asunto reside en la poca unión entre las diferentes congregaciones protestantes, pues mantienen espacios estancos propios de cada comunidad. Aunque algunas realizan encuentros ecuménicos son pocos los contactos entre ellas. Cada comunidad protege lo suyo, quizá por ese talante individual y local característico de la sociedad norteamericana. Como señalan Odgers y Ruiz, (2014, p. 78)

Lejos de las interpretaciones sobre resaltan las influencias externas — sobretodo estadounidenses- del pentecostalismo en la población latinoamericana y tomando a modo de ejemplo el caso de la iglesia de los apóstoles y los profetas en el área metropolitana de Washington D. C., deja de manifiesto en la incorporación

\footnotetext{
8 La CASA Maryland surgió hace 32 años en Maryland, cerca del D. C., concretamente en Langley Park. Se reunieron una serie de refugiados centroamericanos, en una iglesia Presbiteriana para hablar y tratar el asunto de los inmigrantes de esa parte de América. Destacan dos aspectos, por un lado a medida que ha ido adquirieron más cuerpo, la CASA Maryland ha dotado de mayores ayudas, laborales, sanitarias, etc., similares al de Immigrant and Refugee Services de Charities Catholic en Washington D.C., creada hace casi 50 años. En segundo lugar inicialmente daba cobertura a ciudadanos procedentes de Centroamérica, hoy, a todos los inmigrantes y ciudadanos norteamericanos desprotegidos.
} 
en la región no sólo de trabajadores extranjeros sino de instituciones religiosas propias de sus sociedades de procedencia. Estas iglesias fundadas por inmigrantes salvadoreños se establecen y mantienen siguiendo patrones socioculturales propios de El Salvador. Más aún si tenemos en cuenta el hecho de que estas iglesias están integradas prácticamente por población salvadoreña y su descendencia.

En el caso de los católicos, las diferentes diócesis cuentan con oficinas para hispanoparlantes y un amplio número dispone de un ministerio hispano. Esto allana las cosas y facilita la cobertura a los diferentes grupos desfavorecidos. Por ejemplo, en Virginia, el seminario propone el aprendizaje del español en los futuros sacerdotes. Muchos lo hablan, bien por ser de ascendencia hispana o por la inquietud de ir a países de habla hispana a aprender el idioma. También es cierto que existen parroquias donde no facilitan ese apostolado hispano. La Archidiócesis de Washington D. C. tiene un servicio de apoyo legal en Caritas que provee de ayuda a los inmigrantes sin recursos. Posee un servicios de salud, una pequeña clínica que presta cobertura sanitaria y odontológica a quienes no pueden pagar la seguridad social o no los cubre la sanidad, los ayudan a encontrar empleo, etc.

Una activista del apostolado católico de Arlington (entrev. VA) "comentaba que realizan un seguimiento de los inmigrantes indocumentados desde el momento que llegan a la parroquia, y el tiempo de residencia en el país. A partir de ese momento se realiza un seguimiento y de dotar a los abogados (la mayoría voluntarios) de información y documentación para presentar y regularizar su situación. [...] El seguimiento del proceso de documentación, normativas, etc., es complejo y tedioso. Una de las tareas es documentar su estancia, no haber cometido ninguna irregularidad, no ha infringido normas, etc., lo que facilita su defensa, [...]. El costo para ellos varía, dependiendo de sus ingresos, la parroquia corre con los gastos, o bien, ellos pagan una parte del proceso [...]. Esta mañana de madrugada, a eso de las 2 am me llamaron dos feligreses de la parroquia, porque había habido un "chivatazo" que a XXX, de El Salvador, iban a ir a buscarlo a su casa miembros de inmigración para deportarlo. Entonces pusimos en funcionamiento la maquinaria y (...) un colectivo de miembros de la comunidad nos movilizamos para llevarlo a otro lugar que inmigración no lo encontrara. Como puedes ver nuestra comunidad intenta ayudar, mantener y defender 
los valores cristianos e hispanos. No todas las parroquias persiguen estos principios, pues algunos son muy anglos y (...)".

En este sentido la doctrina social de la iglesia es un espaldarazo para el desarrollo de una estructura de ayuda a los más desfavorecidos, léase en este caso, la inmigración. Como apunta Mooney (2009, p.71) en un estudio realizado en Montreal, París y Miami extrajo que la iglesia católica en los EE. UU. tenía un impacto positivo entre la población inmigrante, por sus servicios sociales y lograr el éxito en el empleo. Por esta política y búsqueda de oportunidades muchos de los inmigrantes se acerquen a ella buscando una oportunidad.

El colectivo no afiliado a ninguna creencia, aunque no es muy amplio en nuestra investigación por las características de los inmigrantes y de sus países de origen que está afiliado a alguna creencia. Tienen su particular diáspora y no han recibido ayuda de nadie.

Antonio, mexicano (gdisc. DC) sin afiliación religiosa expresaba que tan sólo había recibido ayuda de compatriotas. En el momento de la entrevista se encontraba en una circunstancia complicada, indocumentado pero casado con una ciudadana norteamericana. Estaba con el trámite, pues hacía dos años atrás se lo habían denegado. "Mi llegada a los EE. UU. ha sido muy complicada, en el transito temí por mi vida. Lo he intentado en tres ocasiones, las dos primeras me deportaron a México. Como dice el refrán a la tercera va la vencida, entré sin retorno. En la segunda intentona pensé que moría, lo logré, pero estuve cerca de la muerte en el desierto. Deambule días sin comida y casi sin agua (...), ahí vi la muerte (...), una de las veces que caí por cansancio vi una calavera humana, me levanté rápidamente y seguí sin rumbo hasta que llegue a un lugar donde había agua, y allí me detuvo la migra (policía de fronteras norteamericana). Luego me llevaron a un centro y desde allí de retorno a México. [...] lo volví a intentar y aquí estoy". Nadie me ha ayudado, ni iglesia, ni organizaciones ni nada, tan sólo mi hermano que lleva muchos años en EE. UU. Gracias a él y a un puñado de mexicanos estoy trabajando en restaurantes. Además muchos hispanos, especialmente de Centroamérica, cuando he solicitado ayuda me han dicho que no o me han mareado".

Lorenza (gdisc. MD) "llegué a una comunidad hispana en Maryland, me acerqué a un colectivo de hispanos, procedentes de Centroamérica. Al principio notaba cierta distancia, pequeños desencuentros y algunos feos. Yo soy boliviana, entendí que posiblemente esto tenía raíz en mi carácter, alegre pero un poco rustico [...] a medida que pasaba el tiempo, no conseguía conectar con ellos, [...] pasado un tiempo, 
aparecieron tres inmigrantes ajenos a la comunidad centroamericana, de Sudamérica, entonces el asunto cambió [....] se estrecharon mis relaciones con estas personas, y empezó un distanciarnos con los otros, $[\ldots]$ tras varios comentarios apreciamos como las relaciones se hacían difíciles, entre otras cuestiones porque marcaban la distancia nos llamaban señora, señor, ... la boliviana, el peruano, etc., pero no había acercamiento. Seguimos asistiendo al centro, pero... en espacios diferentes y sin llegar a tener una relación cercana. [...] una de las personas nuevas comentó una situación similar en Virginia, concretamente en Fairfax County".

Esto pone de relieve que a pesar de presentar una realidad similar existe todavía cierto rechazo entre comunidades hispanas. Quizá sería bueno analizar en profundidad actitudes de esta índole si pueden ser un revulsivo para la integración de determinados inmigrantes en un "territorio" dominado por inmigrantes hispanos procedentes de diferente área geográfica. Además, puede generar una "autoguetización territorial" de hispanos en EE. UU.

Llevando a cabo un análisis de correspondencias múltiples se comprueba que el colectivo centroamericano indocumentado son quienes más ayuda recibe de la iglesia. Los mexicanos recurren menos a las ayudas. Dos cuestiones destacan en ellos, que llevan décadas pasando por esta realidad y conocen mejor el terreno y una mayor posesión de la Green Card. Los suramericanos también acuden a las ayudas de la iglesia, en menor medida que los centroamericanos, y hay más personas regularizadas.

GRÁFICO 7

Gráfico simétrico de las variables (ejes F1 y F2: 80,70\%)

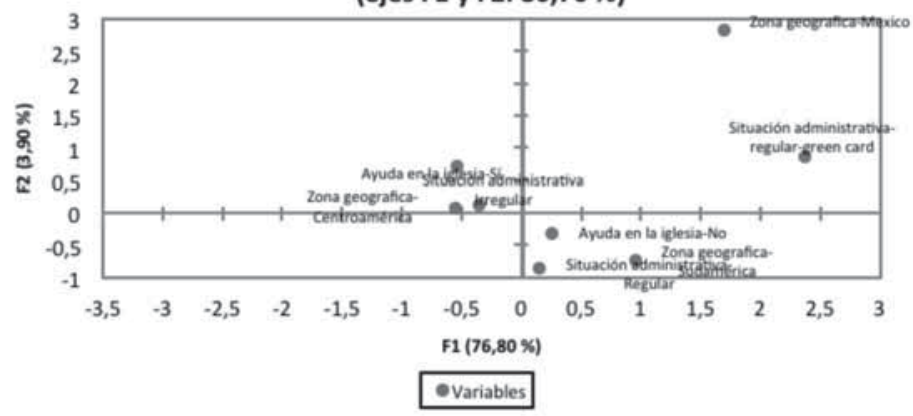

Fuente: elaboración propia. 
Fijándose en el gráfico 8 y conectándolo con la tabla 1 se descifra que los hispanos indocumentados suelen estar más vinculados a la los grupos religiosos, a la iglesia católica y recibir ayuda de la iglesia.

TABLA 1

Tabla cruzada Zona Geográfica*Uso de servicios religiosos

\begin{tabular}{|c|c|c|c|c|c|}
\hline & \multicolumn{2}{|c|}{$\begin{array}{l}\text { Uso de } \\
\text { servicios } \\
\text { religiosos }\end{array}$} & \multirow{2}{*}{$\begin{array}{c}\text { Tota } \\
1\end{array}$} \\
\hline & & & No & Sí & \\
\hline \multirow[t]{3}{*}{$\begin{array}{l}\text { Zona } \\
\text { Geográfic } \\
\text { a }\end{array}$} & $\begin{array}{l}\text { Centroam } \\
\text { érica }\end{array}$ & $\begin{array}{l}\text { Recuento } \\
\% \text { dentro de } \\
\text { Zona Geográfica }\end{array}$ & $\begin{array}{r}55 \\
40,1 \%\end{array}$ & $\begin{array}{r}82 \\
59,9 \%\end{array}$ & $\begin{array}{r}137 \\
100 \\
0 \%\end{array}$ \\
\hline & $\begin{array}{l}\text { Sudaméri } \\
\text { ca }\end{array}$ & $\begin{array}{l}\text { Recuento } \\
\% \text { dentro de } \\
\text { Zona Geográfica }\end{array}$ & $\begin{array}{r}23 \\
39,0 \%\end{array}$ & $\begin{array}{r}36 \\
61,0 \%\end{array}$ & $\begin{array}{r}59 \\
100 \\
0 \% \\
\end{array}$ \\
\hline & México & $\begin{array}{l}\text { Recuento } \\
\% \text { dentro de } \\
\text { Zona Geográfica }\end{array}$ & $\begin{array}{r}10 \\
83,3 \%\end{array}$ & $\begin{array}{r}2 \\
16,7 \%\end{array}$ & $\begin{array}{r}12 \\
100 \\
0 \%\end{array}$ \\
\hline Total & & $\begin{array}{l}\text { Recuento } \\
\% \text { dentro de } \\
\text { Zona Geográfica }\end{array}$ & 88 & $\begin{array}{r}120 \\
57,7 \%\end{array}$ & $\begin{array}{r}208 \\
100 \\
0 \%\end{array}$ \\
\hline
\end{tabular}

Fuente: elaboración propia.

Generalmente, los evangélicos no recurren a los servicios religiosos y pocos solicitan ayuda de la iglesia, posiblemente se deba a desconocimiento. Los protestantes van por libres no recurren a las ayudas y casi no participan de los grupos religiosos. 
GRÁFICO 8

\section{Gráfico simétrico de las variables}

(ejes F1 y F2: 78,31 \%)

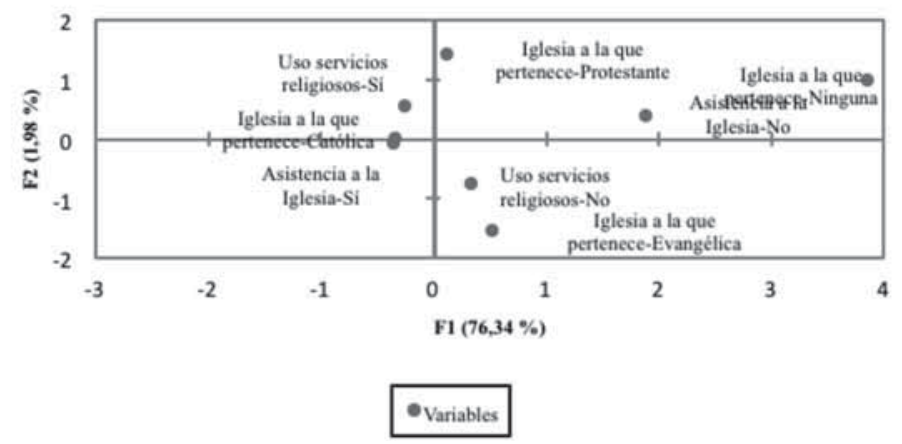

Fuente: elaboración propia.

Centrándonos en cuestione básicas, el capital de enlace y vinculación puede desempeñar un papel importante en el proceso migratorio. Por ejemplo, los latinos nacidos en el extranjero pueden encontrar más apoyo y estar más integrados en las comunidades dominadas por las denominaciones puente como el catolicismo y el protestantismo principalmente. Por otro lado, el estrés económico y emocional puede exacerbarse en comunidades dominadas por denominaciones vinculantes.

En segundo lugar se demuestra que las diferentes iglesias ayudan a los inmigrantes a encontrar un puesto de trabajo. Siendo la iglesia católica quien más apoyo presta en esto y en cobertura social y espiritual ante la situación de inestabilidad administrativa de muchos de ellos.

\section{OBSERVACIONES FINALES}

Del estudio realizado (tanto en su dimensión cuantitativa como cualitativa) cabe destacar las siguientes conclusiones sobre la inmigración hispana y su relación con las iglesias en estas áreas:

Los hispanos en situación irregular están más identificados con la iglesia, y por ende son más activos en su participación en los grupos de acción religiosa, y perciben ayudas de dichas comunidades. Lo cual 
resulta comprensible, puesto que cuando alguien se encuentra ante una realidad complicada recurre a quien puede ayudar, y máxime cuando se identifican con una creencia. También es cierto que muchos inmigrantes no sólo se han visto ayudados por las iglesias stricto sensu, sino por otras organizaciones relacionadas como CASA Maryland o Cáritas sin requerir de una afiliación a las mismas. Cuando su situación es regular, la participación en los grupos religiosos se reduce sensiblemente.

Existe cierta separación entre miembros de las iglesias, por un lado, entre los de ascendencia anglosajona y otras (en concreto la hispana objeto de estudio). Aun cuando, la adscripción a una lengua o grupo nacional no puede ser elemento diferenciador de comunidades dentro de una misma iglesia. En algunos casos, los propios hispanos destacan la diferencia porque desean seguir manteniendo sus parámetros culturales y festejar el encuentro comunitario atendiendo a sus modelos culturales. También es cierto que determinados colectivos de inmigrantes hispanos, nacionalizados o de segunda generación desean seguir marcando esa identidad étnica y excluyen indirectamente mediante el idioma a los nativos americanos por no pertenecer a esa minoría étnica-nacional. Tal y como reflexionaba una pastora protestante de Arlington (entrev. VA) y que arrojó mucha luz en las relaciones en anglos e hispanos. "La comunidad anglo nos ha dejado este pequeño templo para que podamos dar servicio religioso a los hispanos, ellos hacen sus fiestas en sus horas de comunidad y nosotros hacemos las nuestras. Entonces ¿Ustedes no participan de sus fiestas? "Por lo general no, sólo en alguna ocasión muy especial, muy especial". Cabe recordar que cuando me acerque a la iglesia anglo para preguntar por el pastor y hablar con él, una miembro de la comunidad anglo me contestó: "It's not here, It's there". O la apreciación de un pastor evangélico con quince años de residencia en Prince George's County (entrev. MD) sobre la relación anglo/hispano, "la comunidad anglo nos arrienda el templo. Así que tenemos que pagar un dinero a la comunidad anglo por las celebraciones dominicales, tener reuniones religiosas, celebrar fiestas y asistir los jueves a la lectura evangélica”. Por otro están las discrepancias entre hispanos/hipanos atendiendo a las áreas geográficas nacionales, como lo han hecho saber pastores, sacerdotes o miembros de apostolados hispanos. Como se ha antedicho, una feligrés de la iglesia católica tuvo muchos inconvenientes con personas procedentes de Centroamérica, aun cuando practican la misma fe. Por otra parte, una pastora evangélica hispana (entrev. VA) manifestaba que las 
relaciones entre hispanos no siempre eran amistosas: "tengo dos templos hispanos en la zona (Falls Church y Fairfax) a una acuden hispanos de Sudamérica y a la otra hispanos de Centroamérica. Rara vez asiste algún miembro de la otra comunidad o de diferente área geográfica. Entre ellos no se llevan demasiado bien".

Los indocumentados son más activos en la participación religiosa frente a quienes están regularizados. Esto va en la línea de lo expresado por Cadge and Ecklund (2006) los inmigrantes que están menos integrados en la sociedad estadounidense son más propensos que otros a acudir al servicio religioso con regularidad.

El proceso migratorio produce cambios de creencias. Tomando nuestras las observaciones de Connor, (2014:) tras el proceso migratorio se produce unos cambios en la fe de los inmigrantes tanto para los varones como para las mujeres en la identidad como en la práctica religiosa. Aunque, algunos inmigrantes se mueven de unas a otras denominaciones cristianas o hacia tendencias sin afiliación religiosa, la mayoría mantienen su credo (p.117-118). Un claro ejemplo fue Marilia, hondureña (gdis. VA) "yo era católica pero cuando llegue a los EE. UU. me encontré que no había ninguna iglesia católica cerca, pero quería seguir practicando la fe. Mirando localicé un templo evangélico cerca de mi vivienda y empecé a acudir. Ahora asisto con mi esposo. He cambiado de creencia, pero es lo mismo porque en el fondo es el encuentro con Dios".

En algunos contextos donde sus religiones son marcadamente muy diferentes de la religión mayoritaria del país de acogida, su identidad religiosa puede ser más importante de lo que era antes de mudarse. Se observa como en el colectivo, especialmente en situación irregular, la religión se transforma en su principal proyecto de vida. Interiorizando una satisfacción de acogida, de estabilidad y de futuro a su nacionalización. Tal y como han expresado algunas personas entrevistadas, la práctica religiosa es una necesidad y una obligación. Antes asistían a la misa, y como ellos señalan sin esa espiritualidad e interioridad de como lo hacen en EE. UU.

Por último, a nuestro juicio no solo las tres R de Hirschman dotan a la religión de sentido en el proceso migratorio, sino que las iglesias en sus diferentes denominaciones proveen al inmigrante de una dignidad como persona, relanzan su espiritualidad como miembro de una comunidad religiosa y sobretodo, le hacen creer en sí mismo, como miembro de una sociedad que le aporta nuevas oportunidades y expectativas de vida. 


\section{BIBLIOGRAFÍA}

Aguilera-Titus, A., \& Figueroa-Deck, A. (2012). Immigration and American popular culture: An introduction nation of nations. Washington, D. C.: USCCB.

Alexander, J. (2006). The Civil Sphere. New York: Oxford University Press.

Ambrosini, M. (2008). Participación religiosa e integración de los inmigrantes. Una reflexión entre América y Europa, entre historia y actualidad. Migraciones, [S.1.], 23, 11-44.

Barranco, R. E. (2016). Suicide, Religion, and Latinos: A Macro-Level Study of U.S. Latino Suicide Rates. The Sociological Quarterly, 57, 256-281.

Cadge, W. y Ecklund, E. H. (2006). Religious Service Attendance among Immigrants: Evidence from the New Immigrant Survey-Pilot. American Behavioral Scientist, 49(11), 1574-1595.

Castleberry, J. L. (2015). The New Pilgrims: How Immigrants are Renewing America's Faith. Franklin: Worthy.

Chen, C. (2008). Getting Save in America. Taiwanese's Immigration and Religious Experience. Princeton: Princeton University Press.

Connor, Ph. (2014). Immigrant Faith: Patterns of Immigrant Religion in the United States, Canada, and Western. New York: New York University Press.

D’Antonio, W.V., Dillon, M., \& Gautier, M. L. (2013). American Catholics in Transition. Lanhan: Rowman \& Littlefield.

Department of Homeland Security: Year book of Inmigration Stadistics. Recuperado de https:/www.dhs.gov/sites/default/files/publications/ois_ yb_2014.pdf).

Díaz, H. L. D. (2006). El desarrollo socioeconómico de los hispanos en los Estados Unidos de América. En busca de una teoría. En T. Calvo Buezas (Ed.), Hispanos en Estados Unidos, inmigrantes en España: ¿amenaza o nueva civilización? (pp. 100-116). Madrid: Catarata.

Espinosa, G., Elizondo, V., \& Miranda, J. (2003). Hispanic Churches in America Public Life Summary of Finding. Notre Dame: Institute for Latin Studies of the Notre Dame University.

Fole, M.W., \&. Hoge, D. R. (2007). Religion and the New Immigrants How Faith Communities Form Our Newest Citizens. New York: Oxford University Press.

Herberg, W. (1955, 1986). Protestant-Catholic-Jew. An Essay in American Religious Sociology. Chicago: Chicago University Press.

Hirschman, C. (2004). The Role of Religion in the Origins and Adaptation of Immigrant Groups in the United States. International Migration Review, 38, 1206-1233.

Hondagneu-Sotelo, P. (2007). Doméstica: Immigrant workers cleaning and caring in the shadows of affluence. Berkeley: University of California Press. 
Hondagneu-Sotelo, P., Gaudinez, G., Lara, H., \& Ortiz, B. (2004). There is a spirit that transcends the border's: faith, ritual, and postnational Protest at the U.S.-Mexico Border, Sociological Perspectives, 47(2), 133-159.

Honneth, A. (2007). Disrespect: The normative foundations of critical theory. Cambridge, UK: Polity Press.

Kivisto, P. (2014). Religion and Immigration: Migrant Faiths in North America and Western Europe. Malden: Polity Press.

Levitt, P. (2004). Redefining the Boundaries of Belonging: The Institutional Character of Transnational Religious Life, Sociology of Religion, 65(1), 1-18.

Levitt, P. (2003). You know Abraham was really the first immigrant: religion and transnational migration, International Migration Review, XXXVII(3), 847-873.

Lim, Ch., \& Putnam, R. D. (2010). Religion, Social Networks, and Life Satisfaction. American Sociological Review. 75 (6), 914-933.

Mooney, M. (2009). Faith Makes Us Live: Surviving and Thriving in the Haitian Diaspora. Berkeley: University of California Press.

Mulder, M.T., Ramos, A.I., \& Martí, G. (2017). Latino Protestants in America: Growing and Diverse. Lanhan: Rowman \& Littlefield.

Odgers Ortiz, O., \& Ruiz Guadalajara, J.C. (2014). Migración y creencias. Pensar la religión en tiempos de movilidad. Tijuana: Colegio de la Frontera Norte.

Pew Research Center: "Hispanic/Latino demographics" Recuperado de http://www.pewresearch.org/topics/hispaniclatino-demography/.

Rivera-Sánchez, L. (2007). Migrantes entre México y los Estados Unidos: la construcción de espacios públicos desde el campo religioso transnacional. Revista Enfoques Ciencia Política y Administración Pública, 7, 253-276.

Soysal, Y. (1994). Limits of Citizenship: Migrants and Postnational Citizenship in Europe. Chicago: University of Chicago Press.

Taylor, P. (dir.) (2012). Latinos, Religion and Campaign 2012. Washington DC: Pew Hispanic Center.

Treviño, R. (2006). The church in the Barrio: Mexican American EthnoCatholicism in Houston. Chapel Hill: The University of North Carolina Press.

Tönnies, F. (2009). Comunidad y asociación. Granada: Comares.

Vázquez, M., \& Friedman, M. (2003). Globalizing the Sacred: Religion across the Americas. New Jersey: Rutgers University Press. 
